\title{
Medicine as a performing art: a worthy metaphor
}

\author{
Fames $O$ Woolliscroft ${ }^{1}$ E Robert Phillips ${ }^{2}$
}

Purpose Despite numerous calls for reform over several decades, medical educators have been unable to address many significant challenges. Potentially, employing new metaphors and looking at the teaching and learning of medicine in a new way will facilitate the development of creative solutions.

Main findings In this paper we propose the metaphor of medicine as a performing art. Building on this metaphor, string music education is compared to medical education.
Principal conclusions Looking to string education as a model, suggestions for reorganisation of learning experiences, academic structure and assessment are discussed. Medical educators are encouraged to think about the challenges they face in creative ways. By looking outside traditional medical education, solutions may be found to new and old educational dilemmas.

Keywords medical education; performing arts; string music education.

Medical Education 2003;37:934-939

\section{Introduction}

The challenges facing medical education are numerous. For example:

1 What conceptual models incorporating the dramatically expanding understanding of the molecular and genomic scientific bases upon which medicine is built are best for medical educators to impart to our students?

2 What framework should medical educators teach students that will equip them to choose the most appropriate diagnostic and therapeutic approaches for their patients from the multitude of available options?

3 As care delivery has migrated from inpatient to ambulatory sites, what teaching methods will best function under the constraints imposed by ambulatory and community settings?

Add in calls for instruction regarding the economics of medical care, nutrition, biomedical ethics, alternative medicine, medico-legal issues, public health and the practice of population-based medicine, and the scope of the educational challenges faced by medical educators begins to emerge. Further confounding these

\footnotetext{
${ }^{1}$ University of Michigan Medical School, Ann Arbor, Michigan, USA ${ }^{2}$ Saline Public Schools, Saline, Michigan, USA

Correspondence: James O. Woolliscroft MD, University of Michigan Medical School, 1301 Catherine Street, 4101 Medical Science Building I, Ann Arbor, Michigan 48109-0624, USA. Fax: 001734 763 4936; E-mail: woolli@umich.edu
}

instructional demands are the external pressures that beset academic health centres, ranging from declining clinical revenues that result in the need for faculty to increase their clinical and research productivity to the move for increased accountability.

The perception of a need for fundamental change in medical education in the face of what at times appear to be insurmountable problems did not just develop suddenly. Indeed, the need for new approaches to medical education has been recognised for years. In 1989 a survey of nearly 1400 faculty members, department heads and deans in the USA reported that $61 \%$ of these medical educators believed that medical student education required fundamental changes and/or reform. ${ }^{1}$ Interestingly, the majority made similar assertions regarding their own educational programmes. Moreover, they were concerned that medical education in their institutions had not kept pace with changes in the way medicine is practised. International blue ribbon panels $^{2}$ as well as national panels in the USA, ${ }^{3,4}$ the $\mathrm{UK}^{5}$ and Canada $^{6}$ have issued reports calling for fundamental medical education reforms. ${ }^{7,8}$

Why, despite repeated calls for reform and numerous curricular revisions at medical schools across the globe, is there the sense that we have been unable to address fully the problems underlying these reform proposals? ${ }^{7}$ Multiple reasons for this failure have been advanced, ranging from the evolution of medical schools into organisations where education is subservient to research and clinical missions, ${ }^{8,9}$ to the conflicting interests of the groups responsible for medical 


\section{Key learning points}

How we frame a problem sets limits on its potential solutions. When we approach a problem with the mindset that helped create it, we are less likely to discover creative solutions.

String music education suggests alternative approaches to the challenges facing medical education.

Looking to other disciplines might reveal potential solutions to the longstanding and newly arising educational dilemmas facing medical educators.

education, including medical schools and, in the USA, accreditation bodies. ${ }^{3}$ Might, however, this inability to develop creative new responses reflect how we frame the problem? The framing of a situation or problem sets constraints around potential solutions.

One of the ways we frame situations is through our use of metaphors. When we think of medicine, the metaphor most used refers to medicine as a science. This was first set forth in the mid-1800s, when a scientific basis for medicine was a promise and a hope rather than a reality. Regardless, the public and the profession embraced the framing of medicine as a science. As Ludmerer details in Learning to Heal, ${ }^{10}$ this framing led to the development of academic medical centres as we currently know them. However, medical educators have noted the limitations of the metaphor of medicine as a science for decades. In 1927, in a talk to students at Harvard Medical School, Francis Peabody noted: 'The practice of medicine in its broadest sense includes the whole relationship of the physician with his patient. It is an art, based to an increasing extent on the medical sciences, but comprising much that still remains outside the realm of science. The art of medicine and science of medicine are not antagonistic but supplementary to each other. ${ }^{11}$ This tension between the 'art of medicine' and the 'science of medicine' persists in our educational institutions. Embodied in the phrase 'art of medicine' is the realisation that the application of the scientific basis of medicine in the context of clinical care requires the ability to communicate with, to understand and to partner with the person who is the focus of care. It refers to many aspects of clinical practice that are not readily subject to traditional biomedical research. ${ }^{12}$ In contrast, the 'science of medicine', although continuously changing, can be studied dispassionately and provides the knowledge upon which the clinical practice of medicine is based. But are either the science or the art of medicine, divorced from one another, really medicine? The embedding of the science in the context of human interaction is what characterises medicine. Why then do we perpetuate this separation of the art from the science for the purposes of teaching and learning medicine? To allow us to explore and engage in dialogue regarding solutions to what sometimes seem to be inexplicable problems in medical education, it may be helpful to consider how we frame the task we face as teachers of medicine. As Albert Einstein noted, 'The significant problems we face cannot be solved by the same level of thinking that created them. ${ }^{13}$ We propose that another way of framing and thinking about medicine is as a performing art. In this paper we will discuss how this metaphor might guide medical education.

Let us consider some of the parallels between the performing arts, specifically, for this discussion, string music performance, and the practice of medicine.

1 In musical performance, musicians combine technical skills and knowledge of the 'rules' that define a musical genre with the 'interpretation' needed to create a performance. Within, and often across, musical genres, there is a commonality of musical knowledge among musicians. Similarly, within and across the specialties of medicine, there is a shared understanding of the scientific and cultural bases of clinical medicine.

2 Within performing groups, musicians play different roles and have developed expertise on different instruments. There is a shared knowledge and purpose; however, at the individual level expertise differs. Likewise, many patients require the care of doctors from different specialties. There is a shared focus on treating the patient, but the contributions of different members of the care team are unique.

3 In music, no 2 performances are identical; the listeners, the musicians, the venue all shape the performance. At the most basic level, what the audience considers quality music depends on the culture of the listeners; for example, some Eastern music sounds 'foreign' to Western ears. Similarly, each patient encounter differs. Even when the underlying disease process is the same, the approach to the patient and treatment is modified by patient expectations and bounded by cultural definitions of the patient's and doctor's roles.

Given these parallels, let us develop the metaphor of medicine as a performing art to see whether educational strategies from this domain might inform medical 
student education. To begin the dialogue we will consider 5 areas of potential relevance: the purpose of education, the road to mastery, the role of the instructor, academic organisation and assessment.

\section{Purpose of education: performance}

Firstly, the primacy of performance is unquestioned in music education. Whether the novice student is learning about rhythm, pitch or component technical skills, all instructional activities are geared to performance. An example is bowing, which is a fundamental skill that requires specific attention in the novice player. As the student advances, more complex bowing concepts are introduced. At all levels, bowing skills are taught with the final goal of performance clearly in mind. Bowing skills are never presented as a discipline unto itself, but are always embedded in the performance context in which the skills will be applied.

Applying this to medical education, the practice of medicine is established as the direct goal on which all of our educational activities are focused. Instruction is modified based on the level of the student, but always directed toward what is necessary to become proficient in clinical medicine. Abraham Flexner expressed this need for attention to the final goal of medical education as: '...medical education is a technical or professional discipline; it calls for the possession of certain portions of many sciences arranged and organised with a distinct practical purpose in view. That is what makes it a "profession""14 Unfortunately, especially at the medical student level, medical educators have too frequently lost this clarity of purpose. The sciences basic to medicine and even clinical rotations are viewed as autonomous entities rather than as parts of a continuum leading to the ultimate goal of preparing a doctor who can positively affect patient outcomes. As educators, we focus on intermediary process steps without clearly considering how the intermediaries contribute to or detract from the ability to provide patient care. Such fractionisation is not acceptable when medicine is viewed as a performing art and the goal of the educational process is clearly clinical interaction. Viewing medical education in this light requires medical educators to consciously consider how each course and learning experience directly contributes to the final goal of preparing a student for the practice of medicine.

\section{The road to mastery}

Framing medicine as a performing art leads naturally to the conclusion that learning involves 'real practice'.
The concepts of engagement in authentic work, albeit initially at a simple level, are intuitive. Moreover, this framing highlights the risk medical educators are running as learners are less and less involved in hands-on patient care due to concerns for efficiency and misguided regulations regarding oversight. Just as in music, the nascent doctor must be allowed to perform, at an appropriate level, under the watchful eye of an instructor.

From this vantage it is clear that it is also important that the types of patients we have our students work with and learn from be carefully considered. A string music teacher might begin his/her students on simple tunes such as 'Twinkle, Twinkle Little Star', allowing them to hear and play variations on the theme to learn concepts such as rhythm and bowing. Then, as they master the fundamentals, they gradually advance to simplified arrangements of symphonies. Just as the string music teacher would not think of having novice or even intermediate level students attempt to play a Bach concerto, so too medical educators should carefully consider the types of patients students are expected to learn from at each stage of their development. Given the complexity of many cases of chronically ill patients, perhaps medical students should begin learning in clinical settings where they will see relatively simple problems, such as walk-in clinics, student health centres, schools, etc., until they are proficient at the basics. Only then should they progress to clinics and hospitals where complex problems are managed.

Using this frame would also help clarify questions such as whether and how to include 'orphan topics' such as palliative care or nutrition. If a topic is directly related to the performance of clinical care at the level of the learner, it is included. This same screen applied to existing curricula would also help identify material that should be removed. The focus on clinical performance facilitates a reasoned approach to what constitutes the medical education curriculum.

\section{The instructor}

'No student intentionally plays out of tune. They don't know what they are supposed to sound like.' (RP) The same can be said for medical students; no student intentionally sets out to be a bad doctor. In string music education, recordings may be used to demonstrate the desired rhythm and melody or the instructor models a technique or approach to what the student is to play. This provides the student with an example to emulate. The student knows what the instructor is seeking to achieve because there is a clear model to strive toward. In contrast, in medicine we too rarely allow students to 
see a truly expert clinical performance as a target for emulation. We tell students that it is important to communicate with the patient, to synthesise data, to allow the patient to set the clinical agenda, to practise in an ethical and compassionate manner, yet we often do not consciously show them what this 'looks like' in practice. Within the last 50 years we have eliminated many opportunities for students to observe truly masterful clinical performances. In the USA, the classic grand rounds, where the most senior members of the department would examine an actual patient, talking through their diagnostic and therapeutic thought processes, have given way to state-of-the-art summaries of research or clinical topics. ${ }^{15,16}$ Bedside teaching and demonstration by the attending on rounds have been replaced by staffroom and hallway discussions. ${ }^{17}$ Too frequently, a resident is the only model many medical students on hospital wards have to emulate.

As medical education has moved into community settings, students are interacting directly with their preceptors. However, the logistics of placing students in ambulatory practices mean that not all students have the opportunity to observe and learn from exemplary clinicians. Moreover, the realities of teaching in a busy ambulatory practice are such that students may not be afforded the opportunity to observe their preceptors thinking about, working through and reflecting on clinical problems.

If we apply insights gleaned from teachers in the performing arts, the importance of providing the best possible clinical models for medical students to emulate cannot be overemphasised. Just as it is possible to have a string student listen to various interpretations by several conductors and orchestras of a given work, so too students of medicine need the opportunity to observe multiple expert clinicians in action. Ideally, these observations are coupled with explanations so that students can identify and attach clinical behaviours to the words their instructors use. Obviously, there should be a gradation of focus based on the level of the students. However, even at the novice level, exposure to expert clinicians is valuable to allow students the opportunity to see how their learning will help them build toward the goal of becoming complete clinicians. We suggest that medical educators should provide students with multiple opportunities to observe and reflect upon truly expert clinicians in clinical contexts employing the skills that the students are learning.

\section{Academic organisation}

One of the authors of this paper (RP) has served as leader of the string music programme in a public school district for over 25 years. He requires that members of his faculty teach students at all levels, from the novice to the most accomplished. The reason for this is to ensure that all faculty members understand the importance to future performance of what they are teaching, even at beginner's levels, and, just as importantly, understand how difficult it is to teach the fundamentals. Successful grounding in these fundamentals is necessary to ensure that problems are avoided, sometimes many years later, as students are challenged with ever more complex musical pieces.

In many medical schools instructors rarely have the opportunity to observe repeatedly their students as they progress to more advanced levels to see whether or not the fundamentals taught in early courses are understood, integrated and applied. Hence, instructors of the sciences basic to the practice of medicine have little feedback as to the success or failure of their instructional efforts. Similarly, clinical faculty have little appreciation of the difficulties encountered in teaching the fundamentals as they infrequently participate fully in the teaching of novice medical students. How can teaching improve if there is no feedback loop to the faculty responsible? The fact that there may not be dialogue amongst faculty concerning agreement on the key principles foundational to a lifelong practice of clinical medicine compounds the problem further. The insularity of many courses and clerkships within medical schools suggests that we as faculty do not appreciate how our contribution fits into the bigger picture. Moreover, based on the function of many curriculum committees, the decision as to what is fundamental for students to learn at a given level is left to the discretion of departments or even individual faculty members, with minimal or no input from the faculty as a whole. To build upon our analogy, this would be equivalent to allowing the string music instructor who teaches novice musicians to decide unilaterally whether or not to teach the principles of left hand mechanics and fingering.

We suggest that medical school faculty be organised in accountable teams spanning the continuum of education and including basic science and clinical instructors. These teams would be responsible for students' performances in major areas. For example, there might be an anatomic/imaging team that would be responsible for education ranging from functional anatomy to the appropriate use of imaging technology for diagnosis of common presenting complaints. Each team would be charged with deciding which principles are truly basic to the practice of medicine, the appropriate times and educational experiences for the principles to be taught and expanded upon, and the level of performance appropriate to the learning objectives. 
These faculty teams would also be responsible for improving their instructional efforts based on the students' performances. Just as the orchestral conductor is judged by the orchestra's performance, so would each team be accountable for the students' learning.

\section{Assessment}

In string education, it is musical performance that is assessed. While music theory, acoustics and the physics of sound are important to the understanding of music, they are not the focus for assessment of novice and intermediate string players. So too in medical education should the student's ability to perform clinically at an appropriate level be the focus of assessment. This requires an entirely new focus for evaluation in medical education. Medical students' assessments should be based on a synthesis of knowledge and skills measured through an applied clinical performance. If a subject cannot be assessed through a clinical situation, it begs the question as to why students are being asked to learn it. The UK General Medical Council publication Tomorrow's Doctors ${ }^{18}$ and the Association of American Medical Colleges' Medical School Objectives Project ${ }^{19}$ are 2 examples of expected outcomes for medical student education. The majority are behavioural outcomes that readily lend themselves to performancebased assessment. While we acknowledge that the assessment of clinical performance is more difficult than the assessment of intermediary processes, it represents a challenge that medical educators must embrace.

\section{Conclusion}

William Welch, founding dean of the Johns Hopkins University School of Medicine in 1910, stated: 'The fundamental object of medical education is to make good doctors. Without question, that should be the underlying conception in all schemes of medical education, and unless a given course of study bears on that training, it should not have a place in the medical curriculum. If training in physiology even cannot be shown to make good doctors it is not defensible. The same could be said about pathology or any other subject in the curriculum. The ultimate aim of medical education is to make good practitioners of medicine. ${ }^{20}$ This fundamental goal for medical education remains true today. As metaphors provide us with a way to think about a topic, we suggest that medicine as a performing art is a metaphor worthy of consideration. Just as applying the metaphor of medicine as a science led to the creative development of new educational processes in the late 1800 s, so too framing our task differently might provide the creative freedom necessary to meet the challenges medical educators presently face. Considering medicine as a performing art provides a starting point for a dialogue among medical educators, from which we can begin to think in new ways about our educational tasks and creatively move forward to address the needs of our students and society.

\section{Contributors}

This study was conceived by JOW and is based on observations of and extensive discussions with RP. RP is an internationally known folk fiddling and classical music educator, a fact that led us to focus on string music for the purposes of this paper. The text was written by JOW, with continual input and editing by RP.

\section{Funding}

This work was supported in part by the Josiah Macy Jr. Foundation through the Josiah Macy Jr. Professor of Medical Education Endowed Professorship held by JOW.

\section{References}

1 Cantor JC, Cohen AB, Barker DC, Schuster AL, Reynolds RC. Medical educators' views on medical education reform. FAMA 1991;265:1002-6.

2 Schwarz MR, Wojtczak A. Global minimum essential requirements: a road towards competence-oriented medical education. Med Teacher 2002;24:125-9.

3 Enarson C, Burg FD. An overview of reform initiatives in medical education 1906 through 1992. FAMA 1992;268:1141-3.

4 Christakis NA. The similarity and frequency of proposals to reform US medical education. Constant concerns. $F A M A$ 1995;274 (9):706-11.

5 General Medical Council. Tomorrow's Doctors: Recommendations on Undergraduate Medical Education. London: General Medical Council 1993.

6 Neufeld VR, Maudsley RF, Pickering RJ, Turnbull JM, Weston WW, Brown MG, Simpson JC. Educating future physicians for Ontario. Acad Med 1998;73:1133-48.

7 Christopher DF, Harte K, George CF. The implementation of Tomorrow's Doctors. Med Educ 2002;36:282-8.

8 Bloom SW. Structure and ideology in medical education. f Health Soc Behav 1988;29:294-306.

9 Bloom SW. The medical school as a social organisation: the sources of resistance to change. Med Educ 1989;23:228-41.

10 Ludmerer KM. Learning to Heal. The Development of American Medical Education. New York: Basic Books, Inc. 1985.

11 Peabody F. The care of the patient. FAMA 1927;88:877-82. 
12 Greco FA. What is the art of medicine? Am $\mathcal{F}$ Med 1985;79:279.

13 Calaprice A, ed. The Expanded Quotable Einstein. New Jersey: Princeton University Press 2000.

14 Flexner A. The Flexner Report on Medical Education in the United States and Canada 1910. New York: Carnegie Foundation 1910;58.

15 Ingelfinger FJ. The graying of grand rounds. $N$ Engl $\mathcal{F}$ Med 1979;299:772.

16 Parrino TA, White A. Grand rounds revisited. Results of a survey of US departments of medicine. Am $\mathcal{F} \mathrm{Med}$ 1990;89:491-5.

17 Mellinkoff SM. The medical clerkship. N Engl f Med 1987;317:1089-91.
18 General Medical Council. Tomorrow's Doctors: Recommendations on Undergraduate Medical Education. London: General Medical Council 2002. http://www.gmc-uk.org/med_ed/tomdoc.htm.

19 Medical School Objectives Project. Learning objectives for medical student education - guidelines for medical schools. Report 1 of the Medical School Objectives Project. Acad Med 1999;74:13-8.

20 Schuster AL, Reynolds RC. Medical education: can we do better? Acad Med 1998;73 (9):5-6.

Received 17 October 2002; editorial comments to authors 9 fanuary 2003; accepted for publication 12 May 2003 